\title{
Uma história da historiografia polemista: José Carlos Reis
}

\author{
A polemicist history of historiography: José Carlos Reis
}

REIS, José Carlos. Teoria e história: tempo histórico, história do pensamento histórico ocidental e pensamento brasileiro. Rio de Janeiro: FGV, 2012, 272 p.

\section{Cristiano Arrais}

cpaarrais@gmail.com

Professor Adjunto

Universidade Federal de Goiás

Rua 1044, 129/903, Ed. Imperial - Setor Pedro Ludovico

74825-110 - Goiânia - GO

Brasil

Palavras-chave

Historiografia; Teoria da história; Escrita da história.

Keywords

170

Historiography; Theory of history; Writing of history. 
Fenômeno importante vem ocorrendo no cenário historiográfico brasileiro dos últimos anos. Historiadores e pesquisadores de áreas diversas têm concentrado esforços no intuito de mapear o processo de constituição do pensamento histórico. No interior deste fenômeno, é possível distinguir três movimentos. Primeiro, a proposta de facilitação do acesso ao público brasileiro a obras e autores, até há algum tempo, pouco conhecidos do público brasileiro, como fazem, por exemplo, Ideias de História (2007), organizado por Marco Antônio Lopes; Lições de história (2010), organizado por Jurandir Malerba e A história pensada (2010), organizado por Estevão Rezende Martins. O segundo movimento, voltado para o aprofundamento e verticalização dos problemas epistemológicos e ético-políticos que envolvem o trato com o passado, tem em obras como A História, a retórica e a crise de paradigmas (2012), de Carlos Oiti Berbert Júnior, e Estudos de historiografia brasileira (2011), organizado por Lucia Bastos, seus mais recentes representantes. Por último, um movimento que visa expor ao público sínteses capazes de condensar as principais ideias, metodologias e discussões epistemológicas da historiografia contemporânea, como apresentado pela tetralogia Teoria da história (2011), de José d'Assunção Barros.

Em que pese o risco de generalização e compartimentalização executado por essa breve classificação historiográfica, é possível identificar duas características relativamente comuns aos três movimentos: a explicitação dos procedimentos explicativos e a preocupação com a referencialidade contextual do campo de pesquisa. Tais características, como lembrou Araújo (2010), são inerentes ao processo reconstrutivo elaborado pelo pensamento historiográfico em seu esforço de flexibilização dos procedimentos teóricos e metodológicos que "sempre estão sob o risco de serem assumidos como produtores de uma verdade impermeável".

O novo livro de José Carlos Reis, Teoria e história, situa-se neste terceiro movimento, que introduz e torna acessível aos historiadores temas associados à epistemologia da história. Seu sumário apresenta artigos escritos em épocas diversas, que tratam de alguns dos mais importantes temas da historiografia das últimas décadas ${ }^{1}$. Uma breve comparação com o sumário de sua obra anterior (História \& Teoria, 2002) demonstra como esses temas são caros ao horizonte de interesses do autor: pós-modernidade, Annales, Dilthey e temporalidade são problemas que, já visitados no primeiro volume, agora retornam nesta nova obra. Este retorno não implica necessariamente numa reedição da abordagem anterior, mas no tratamento do tema a partir de outra perspectiva. Este é o caso do capítulo que abre o volume, sobre o tempo histórico. Além da análise de suas três categorias formais (o passado, local da experiência, do sido, do acontecido e do vivido; o presente, o local da sens/ação, da percepção efetiva da duração

\footnotetext{
${ }^{1}$ A ordem de apresentação dos capítulos é: "O tempo histórico como 'representação'", de 2012; "A historiografia pós-1989: pós-modernismo, representações e micronarrativas", inédito; "Tempo, história e compreensão narrativa em Paul Ricoeur", de 2005; "História da história (1950/1960): história e estruturalismo: Braudel versus Lévi-Strauss", de 2008; "História da história (1900/1930): Henri Berr e a 'nova história' dos Annales", de 2012; "Sobre a 'compreensão' em história: Dilthey (1830-1911) versus (e vice-versa) Weber (18641920)", de 2008; "Os conceitos de liberdade e necessidade em Marx (1848-1890), de 1987; "Comentário final: por um pensamento brasileiro".
} 
e o futuro, "portador tanto da inquietude, da instabilidade, do medo da finitude, quanto da esperança de ser") Reis traça um percurso que distingue o tempo histórico como representação intelectual e como construto cultural, ancorado nas teses de Koselleck, Hartog, Ricoeur e Levinas.

A reunião de trabalhos publicados em momentos diferentes projeta uma identidade híbrida à obra. Isso significa dizer que não há qualquer ordem ou hierarquia capitular a ser seguida pelo leitor que pode, neste caso, produzir um roteiro de leitura adequado aos seus interesses. Àqueles interessados no estruturalismo encontrarão uma síntese segura do diálogo entre história e etnologia, que provocou uma alteração substancial na historiografia francesa a partir da década de 1960. Nesse estudo, Reis reconstrói os principais argumentos deste debate historiográfico, centrando-se nas figuras de Lévi-Strauss e Fernand Braudel. Para alcançar essa reconstrução, o autor retoma a interpretação clássica de Dosse (1992, p. 15), que observa no movimento dos Annales uma estratégia de "captação dos procedimentos, das linguagens das ciências sociais vizinhas, de uma capacidade notável de apoderar-se das roupagens dos outros" e de transformação de seus adversários em aliados por meio da sua incorporação a um programa de trabalho interdisciplinar.

Essa ênfase sintética é marca registrada das obras de José Carlos Reis, podendo o leitor observá-la também no capítulo dedicado a Henri Berr. É este um texto, diga-se de passagem, generoso com o leitor, que, além de disponibilizar ao público brasileiro um artigo de Henri Berr, enfatiza a influência que o movimento dos Annales sofreu desse filósofo, muito embora a mesma tenha sido eclipsada pela própria historiografia dos annalistes. O filósofo Berr - talvez o primeiro a utilizar o termo Nouvelle Histoire para descrever o movimento intelectual que então se formava em torno do combate à história política tradicional (MUCHELLI 1995) - é apresentado como um intelectual empenhado no contato interdisciplinar e na reflexão teórica. Nesse sentido, ao se afastar de Henri Berr, conclui Reis, o grupo de Annales prestou um desserviço à historiografia; separando a pesquisa histórica da teoria da história, trouxe o isolamento e a fragmentação para o campo das ciências humanas. O autor conclui que "sem sua teoria da história [de Berr], aliada à dos durkheimianos, não teria ocorrido a 'revolução francesa na historiografia'"'. Uma conclusão que estimula no leitor o interesse pelo estudo e aprofundamento da trajetória intelectual desse filósofo.

Estímulo semelhante o leitor encontrará em outros dois capítulos. Primeiro, no texto dedicado à diferença entre o conceito de compreensão empática, em Dilthey e Weber. O pano de fundo desse diálogo encontra-se no problema das condições subjetivas de produção do conhecimento sobre o passado. Entre a proposta de apreensão das expressões e manifestações humanas que constituem o mundo histórico-espiritual e uma perspectiva racionalista-conceitualista da compreensão, Reis enfatiza um Dilthey que situa o procedimento compreensivo da história no entrecruzamento com a arte. Já no capítulo dedicado à análise do conceito de liberdade em Marx, o autor procura diferenciar o conceito de liberdade marxiano daquele elaborado por Engels, de influência espinosiana, segundo seu julgamento. Assim, a partir do conceito de liberdade de Espinosa, associado 
à contemplação de Deus, num contínuo processo de crescimento intelectual, Engels teria definido a liberdade como a "consciência da necessidade", obtida por meio do conhecimento prático. Já em Marx, a liberdade se realiza no conceito de práxis, na medida em que pressupõe um movimento de autotransformação e autocriação do sujeito.

Este texto de juventude, escrito em 1987, também possibilita ao leitor estabelecer uma comparação com o único texto inédito do livro, "A historiografia pós-1989: pós-modernismo, representações e micronarrativas". Tal comparação permite ao leitor se aproximar da trajetória intelectual do autor, observar suas empatias teórico-metodológicas e mudanças estilísticas, desde o primeiro trabalho. "O estilo nos trai", lembrou Peter Gay (1990), porque é recurso para se aproximar do processo de aprendizagem do autor, adentrar no mundo de seu ofício. E se o estilo é "a arte da ciência do historiador", o processo de aprendizagem inerente à escrita que José Carlos Reis, reforçou sua identidade ensaística, para além daquela apresentada em obras anteriores. Vale notar que o tom ensaístico possui um dado positivo, na medida em que a obra ganha em termos de liberdade para construir metáforas e fomentar o debate, mesmo sob o risco de reforçar subjetivismo de suas interpretações.

Neste capítulo, a atenção de Reis volta-se para a historiografia contemporânea, pós-1989. Esse recorte está fundamentado no conceito de presentismo, que marcaria o regime de historicidade atual, caracterizado pela substituição de uma história progressista (encarada como ameaça), pelo fortalecimento de uma concepção absolutizada de presente e pela ênfase numa perspectiva antropológica sobre a experiência do tempo (HARTOG 2003). Esse regime de historicidade presentista, que atinge a historiografia, tem como uma de suas principais características a pós-modernidade: "chamemos assim esse mundo pós-1989". Essa por sua vez, segundo Reis, caracteriza-se pela dominação do capital, alienação, lógica do mercado, fatalismo, individualismo e inexistência de alternativas ideológicas, que foram substituídas por uma resistência que não significa oposição à ordem, mas aceitação e luta para "ocupar os melhores lugares, as posições mais vantajosas, obter privilégios, conquistar propriedades, ter acesso a símbolos e situações de poder" (REIS 2012, p. 83). Essa nova cultura histórica "do brilhantismo e da habilidade de comunicação e não da erudição e da defesa de valores universais", teria como marca a empatia com os vencedores. O exemplo mais próximo poderia ser notado no debate historiográfico brasileiro sobre a escravidão: os dois regimes de historicidade encontrados pelo autor (entre 1940-1950: passadista e nostálgico; entre 1960-1970: marxista-futurista) foram abandonados em prol de um terceiro regime de historicidade, em menos de meio século: o regime de historicidade presentista (1980-1990). Nele encontraremos uma historiografia marcada por "juízos de valor completamente presentistas" (Campos da violência, de Sílvia Hunold Lara, 1988) ou influenciada pela "vitória consensual da ordem capitalista" (Chica da Silva e o contratador dos diamantes: o outro lado do mito, de Júnia Furtado, 2003).

Como bem notou Júnia Furtado, na apresentação de Teoria \& História, existe neste capítulo um sentimento de nostalgia de um passado historiográfico 
idealizado pelo autor. A nostalgia de uma época em que as posições historiográficas podiam ser delimitadas em termos dicotômicos. Derivada dessa nostalgia historiográfica, encontraremos um modelo explicativo - "As historiografias ocidental e brasileira não poderiam continuar as mesmas pré-1989, como se o projeto do Leste ainda estivesse em vigor. Elas tinham de mudar para acompanhar o processo histórico" (REIS 2012, p. 18) - fortemente influenciado por um determinismo político-ideológico contestável.

Controverso, polêmico. Esses talvez sejam os termos mais adequados para descrever Teoria e história. Mesmo em seu comentário final - uma exortação à reflexão criativa do legado histórico-filosófico europeu com vistas à criação de um pensamento histórico-filosófico brasileiro - essa identidade não é perdida. Pelo contrário, ela vai ao encontro de seu posicionamento na Introdução da obra e da crítica bastante apropriada a certos barroquismos, que pouco contribuem para a consolidação de um campo tão recente na historiografia brasileira, como é a teoria da história. Afinal, como produtores, comentadores, intérpretes do pensamento historiográfico-filosófico internacional, a historiografia brasileira deve ter o compromisso de garantir a inteligibilidade dessa produção de modo a fomentar o pensamento dialógico e crítico. Evidentemente que o modelo estilístico contrário ao barroquismo, o didatismo, que enfatiza em demasia o trabalho de tradução e interpretação, atingindo a fronteira da superficialidade, é também uma falta grave. Ao provocar no leitor o hábito do caminho mais fácil, do atalho que evita os problemas, as contradições e encruzilhadas, o didatismo vai de encontro às fontes mais férteis para o trabalho intelectual. Teoria \& História caminha entre os extremos enunciados, utilizando o polêmico e o controverso como mote para a reflexão historiográfica.

\section{Referências bibliográficas}

ARAUJO, Valdei Lopes. Sobre o lugar da história da historiografia como disciplina autônoma. Locus: revista de história. UFJF, vol. 12. No 1, 2006.

BARROS, José d 'Assunção. Teoria da história. 4 vols. Petrópolis: Vozes, 2011.

BASTOS, Lucia; GUIMARÃES, Lucia; GONÇALVES, Márcia; GONTIJO, Rebeca (org.) Estudos de historiografia brasileira. Rio de Janeiro: FGV, 2011.

BERBERT, Carlos Oiti. A história e a crise de paradigmas. Goiânia: UFG, 2012.

DOSSE, François. A história em migalhas. Campinas: Editora Unicamp, 1992.

GAY, Peter. O estilo na história. São Paulo: Companhia das Letras, 1990.

HARTOG, François. Régimes d'historicité: presentisme et expériences du temps. Paris: Seuil, 2003.

LOPES, Marco Antônio (org.). Ideias de história. Londrina: EDUEL, 2007.

MALERBA, J. Lições de História. Porto Alegre: EDIPUCRS, 2010.

MARTINS, Estevão Rezende. A história pensada. São Paulo: Contexto, 2010. 
MUCCHIELLI, Laurant. Aux origines de la nouvelle histoire en France: I'evolution intellectuelle et la formation du champ des sciences sociales (1880-1930). Revue de synthèse. № $1,1995$.

REIS, José Carlos. História e Teoria. Rio de Janeiro: FGV, 2003. 